\title{
Ambulatory surgery adult patient selection criteria - a survey of Canadian anesthesiologists
}

\author{
[La sélection des patients adultes en chirurgie ambulatoire - enquête auprès des \\ anesthésiologistes]
}

Zeev Friedman MD, ${ }^{*}$ Frances Chung FRCPC, $\dagger$ David T. Wong MD $\dagger$

Purpose: An increasing number of patients with complex medical problems are now considered suitable for ambulatory surgery. The purpose of this study was to identify the current clinical practice of ambulatory surgical patient selection.

Methods: A standardized questionnaire specifying 30 clinical conditions was sent to all practicing anesthesiologists who are members of the Canadian Anesthesiologists' Society. Recipients were asked to indicate if they would provide ambulatory anesthesia (yes/no answers) for an adult patient with each of those isolated conditions. A 75\% agreement was considered a majority opinion.

Results: One thousand three hundred thirty-seven questionnaires were sent and 774 replies were received (57.8\%). Over $75 \%$ of anesthesiologists were willing to include in their selection criteria American Society of Anesthesiologists' (ASA) physical status III, patients with low-grade angina pectoris (AP) and congestive heart failure (CHF), prior myocardial infarction, asymptomatic valvular disease, sleep apnea without use of narcotics, morbid obesity (MO) without co-morbidities, insulin dependent diabetes mellitus and malignant hyperthermia $(\mathrm{MH})$ susceptible patients. Over $75 \%$ of responders found ASA IV patients, high grade AP and CHF, sleep apnea with postoperative narcotics, $\mathrm{MO}$ with co-morbidities and no patient escort to be unsuitable for ambulatory anesthesia.

Conclusion: Our survey demonstrated that medical conditions with extreme grades of severity (mild or severe) are associated with majority opinion to proceed or not to proceed with ambulatory surgery. Issues with over 75\% agreement reflect the common practice. Similar surveys may form a part of patient selection guidelines development in the future.
Objectif : Un nombre croissant de patients ayant des problèmes médicaux complexes est maintenant admissible à la chirurgie ambulatoire. Nous avons voulu vérifier la pratique clinique courante de sélection des patients pour la chirurgie ambulatoire.

Méthode : Un questionnaire normalisé présentant 30 conditions cliniques a été envoyé à tous les anesthésiologistes en exercice, membres de la Société canadienne des anesthésiologistes. Les répondants devaient indiquer par oui ou non s'ils offriraient une anesthésie ambulatoire à un patient adulte pour chacune de ces conditions isolées. Une adhésion à $75 \%$ était considérée comme une opinion majoritaire.

Résultats : Nous avons reçu 774 réponses pour les 1337 questionnaires envoyés, soit 57,8 \%. Plus de $75 \%$ des anesthésiologistes étaient disposés à inclure dans leurs critères de sélection des patients d'état physique III, selon l'American Society of Anesthesiologists (ASA), qui présentent une angine de poitrine (AP) d'évolution lente et une insuffisance cardiaque congestive (ICC), un infarctus du myocarde ancien, une valvulopathie asymptomatique, de l'apnée du sommeil sans usage de narcotiques, de l'obésité morbide (OM) sans comorbidités, un diabète insulino-dépendant et les patients susceptibles d'hyperthermie maligne peranesthésique. Au-delà de $75 \%$ des répondants ont trouvé l'anesthésie ambulatoire inappropriée pour les patients ASA IV, les cas d'AP et d'ICC de haut degré, d'apnée du sommeil avec narcotiques postopératoires, d'OM avec comorbidités et pour les patients sans accompagnateur.

Conclusion : L'enquête démontre que pour les conditions médicales de sévérité extrême (modérée ou sévère) une majorité accepte ou n'accepte pas la chirurgie ambulatoire. Les enjeux qui recueillent plus de 75 \% d'adhésion représentent la pratique courante. Ce type d'enquête pourrait faire partie de futures directives sur la sélection des patients.

From the Departments of Anesthesia, Mount Sinai Hospital;* and the Toronto Western Hospital, $†$ University of Toronto, Toronto, Ontario, Canada.

Address correspondence to: Dr. Frances Chung, Department of Anesthesia, Toronto Western Hospital, 399 Bathurst Street, Toronto,

Ontario M5T 2S8, Canada. Phone: 416-603-5118; Fax: 416-603-6494; E-mail: frances.chung@uhn.on.ca

Funding: the study was financed by the fund of the Department of Anesthesiology without extramural support.

Accepted for publication September 16, 2003.

Revision accepted February 14, 2004. 
A MBULATORY surgery is practiced in increasing numbers in North America due to various economical and staffing reasons. It is projected that the current movement from inpatient to ambulatory procedures will continue, and by the year 2005, outpatient surgery will represent $82 \%$ of all U.S. surgical volume. ${ }^{1}$ Recent advances in anesthetic practice allow for rapid recovery with minimal adverse effects. Improved perioperative care, along with new minimally invasive surgical techniques, has permitted surgeons to perform an increasing array of procedures on an ambulatory basis. ${ }^{2}$

The cost-containment realized in the shift of care from inpatient to outpatient has prompted a "pushing of the envelope." The result was a change in patient selection criteria, and inclusion of patients with complex medical issues, which were deemed unfit for ambulatory surgery in the past. ${ }^{3}$ While issues such as discharge criteria have well formulated clear guidelines, the issue of patient selection remains to a large extent a matter of individual centres' preferences since there have been very few evidence-based studies on patient selection criteria. ${ }^{3,4}$ The aim of this study was to examine the current clinical practice of ambulatory surgical patient selection and to identify patient selection criteria in ambulatory surgery.

\section{Methods}

After Institutional Research Ethics Board approval, a standardized questionnaire with a prestamped return envelope was sent to all practicing anesthesiologists who are members of the Canadian Anesthesiologists' Society. Recipients were asked to indicate if they would provide ambulatory anesthesia for an adult patient with each of the presented isolated conditions. Answers were limited to yes/no only with an option for comments at the end of the questionnaire. A second questionnaire was sent two months later to all non-responding anesthesiologists.

Although no specific ambulatory surgical procedure was proposed, the accompanying letter explained that these patients might undergo surgeries such as: laparoscopic cholecystectomy, knee arthroscopy or operative hysteroscopy and may require general anesthesia (GA).

The questionnaire specifies 30 clinical situations divided into several sections (Appendix). First, a section dealing with general patient status as reflected by American Society of Anesthesiologists (ASA) physical status class III and IV, since some centres still adhere to ASA I and II ambulatory surgery patients only. Following is a section on cardiac issues dealing with angina pectoris $[\mathrm{AP}$; (class II-IV since AP class I is routinely accepted for ambulatory surgery)] and congestive heart failure $(\mathrm{CHF})$ at increasing severities. Also presented are myocardial infarction (MI) and valvular disease. Morbid obesity (MO) of different grades and associated co-morbidities and obstructive sleep apnea with different anesthetic scenarios compose the next section. The last part of the questionnaire contains nine other miscellaneous controversial issues. All these issues reflect current controversies in ambulatory anesthesia as reflected in the literature or lack of it.

The responses were entered into a computerized database for analysis. Analyses were conducted on a descriptive basis for the complete set of results. A 75\% agreement rate was chosen as a cutoff point for representing majority opinion. This was selected by choosing a more conservative number than the one used in the methodology of the ASA surveys for its guideline formulation process.

\section{Results}

We sent out 1,337 questionnaires and received 627 $(46.8 \%)$ replies within two months. A total of 790 (59\%) questionnaires were received after the second invoice. Sixteen questionnaires were unanswered for different reasons and excluded. There were 166 unanswered questions within the answered questionnaires.

Over $90 \%$ of anesthesiologists were willing to include in their selection criteria ASA III patients, patients with AP Canadian Cardiovascular Society Functional Classification class II, prior (more then six months before surgery) MI, CHF - New York Heart Association class I, asymptomatic valvular disease, low-grade MO without co-morbidities and insulin dependent diabetes mellitus (IDDM). Over 90\% of responders found patients with AP class IV, CHF class $\mathrm{IV}$, and severe MO with co-morbidities to be unsuitable for ambulatory anesthesia. The full results are reported in Table I.

When looking at the over $75 \%$ agreement mark, malignant hyperthermia susceptible (MHS) patients were also found acceptable for ambulatory surgery $(82 \%)$. Answers on issues with over $75 \%$ agreement to proceed with surgery are reported in Table II. Over $75 \%$ agreement not to proceed with surgery also included ASA class IV patients, a prior MI one to six months before surgery, CHF class III sleep-apnea with use of GA and narcotics postoperatively, $\mathrm{MO}$ with a body mass index (BMI) of 35 to $44 \mathrm{~kg} \cdot \mathrm{m}^{-2}$ with associated co-morbidity and patients with no escort. Answers on issues with over $75 \%$ agreement not to proceed with surgery are reported in Table III. 
TABLE I Ambulatory patient selection criteria - agreement or disagreement to proceed with surgery

\begin{tabular}{|c|c|c|}
\hline Presented condition & $\begin{array}{l}\text { Yes } \% \\
n=1337\end{array}$ & $\begin{array}{l}\text { No } \% \\
n=1337\end{array}$ \\
\hline ASA III & 93.9 & 4.5 \\
\hline ASA IV & 17.1 & 82.4 \\
\hline AP II & 96.4 & 2.7 \\
\hline AP III & 66.3 & 32.8 \\
\hline AP IV & 4.0 & 95.3 \\
\hline Prior MI (one to six months) & 15.9 & 83.1 \\
\hline Prior MI (more than six months) & 94.8 & 3.9 \\
\hline CHF I & 93.5 & 6.1 \\
\hline CHF II & 70.3 & 29.3 \\
\hline CHF III & 16.7 & 82.6 \\
\hline CHF IV & 1.3 & 98.4 \\
\hline Asymptomatic valvular disease & 93.4 & 5.3 \\
\hline $\begin{array}{l}\text { Sleep apnea - monitored anesthesia } \\
\text { care (MAC) }\end{array}$ & 91.5 & 7.2 \\
\hline Sleep apnea - RA w/o narcotics & 97.0 & 2.7 \\
\hline Sleep apnea - RA with narcotics postop & 35.3 & 64.0 \\
\hline Sleep apnea - GA w/o narcotics postop & 63.4 & 36.0 \\
\hline Sleep apnea - GA with narcotics postop & 14.7 & 84.2 \\
\hline $\begin{array}{l}\text { Morbid obesity }\left(\mathrm{BMI}=35-44 \mathrm{~kg} \cdot \mathrm{m}^{2}\right) \\
\text { w/o CVS or respiratory co-morbidity }\end{array}$ & 91.0 & 9.0 \\
\hline $\begin{array}{l}\text { Morbid obesity }\left(\mathrm{BMI}=35-44 \mathrm{~kg} \cdot \mathrm{m}^{2}\right) \\
\text { with CVS or respiratory co-morbidity }\end{array}$ & 18.1 & 81.7 \\
\hline $\begin{array}{l}\text { Morbid obesity }\left(\mathrm{BMI}>=45 \mathrm{~kg} \cdot \mathrm{m}^{2}\right) \\
\text { w/o CVS or respiratory co-morbidity }\end{array}$ & 49.5 & 50.1 \\
\hline $\begin{array}{l}\text { Morbid obesity }\left(\mathrm{BMI}>=45 \mathrm{~kg} \cdot \mathrm{m}^{2}\right) \\
\text { with CVS or respiratory co-morbidity }\end{array}$ & 4.7 & 95.2 \\
\hline Insulin dependent diabetes mellitus & 92.8 & 6.6 \\
\hline Malignant hyperthermia susceptible & 82.0 & 17.6 \\
\hline Proven malignant hyperthermia & 49.7 & 49.5 \\
\hline Substance abuse & 69.0 & 29.8 \\
\hline Monoamine oxidase inhibitor treatment & 69.5 & 29.6 \\
\hline Sickle cell anemia & 53.2 & 45.5 \\
\hline Chronic renal failure & 72.2 & 27.4 \\
\hline Age $>90$ & 59.6 & 39.8 \\
\hline No escort & 11.2 & 88.1 \\
\hline
\end{tabular}

Yes $=$ agreement to proceed with surgery; no = disagreement. ASA = American Society of Anesthesiologists physical status; AP = angina pectoris - Canadian Cardiovascular Society Functional Classification; $\mathrm{MI}=$ myocardial infarction $; \mathrm{CHF}=$ congestive heart failure - New York Heart Association Classification; RA = regional anesthesia; GA = general anesthesia; $\mathrm{BMI}=$ body mass index; CVS = cardiovascular.

\section{Discussion}

In our survey we tried to address controversial issues in ambulatory surgery patient selection, while keeping the questionnaire short and clear. For analysis purposes, the patients presented are stable and optimally managed and their conditions isolated, which enabled us to get clear answers. The high return rate of almost $60 \%$ reflects the broad interest in the issue of patient selection across the variety of centres and practices.
TABLE II Ambulatory patient selection criteria with over 75\% agreement to proceed with surgery

\begin{tabular}{ll}
\hline Presented condition & $\%$ \\
& $n=1337$ \\
\hline ASA III & 93.9 \\
AP II & 96.4 \\
Prior MI (more than six months) & 94.8 \\
CHF I & 93.5 \\
Asymptomatic valvular disease & 93.4 \\
Sleep apnea - MAC (monitored anesthesia care) & 91.5 \\
Sleep apnea - RA w/o narcotics & 97.0 \\
Morbid obesity (BMI = 35-44 $\mathrm{kg} \cdot \mathrm{m}^{2}$ ) w/o CVS & 91.0 \\
or respiratory complications & \\
Insulin dependent diabetes mellitus & 92.8 \\
Malignant hyperthermia susceptible & 82.0 \\
\hline
\end{tabular}

ASA $=$ American Society of Anesthesiologists physical status; AP = angina pectoris - Canadian Cardiovascular Society Functional Classification; $\mathrm{MI}=$ myocardial infarction $; \mathrm{CHF}=$ congestive heart failure - New York Heart Association Classification; RA = regional anesthesia; $\mathrm{BMI}=$ body mass index; $\mathrm{CVS}=$ cardiovascu lar.

TABLE III Ambulatory patient selection criteria with over $75 \%$ agreement NOT to proceed with surgery

\begin{tabular}{ll}
\hline Presented condition & $\%$ \\
& $n=1337$ \\
\hline ASA IV & 82.4 \\
AP IV & 95.3 \\
Prior MI (one to six months) & 83.1 \\
CHF III & 82.6 \\
CHF IV & 98.4 \\
Sleep apnea - GA with narcotics postop & 84.2 \\
Morbid obesity (BMI $\left.=35-44 \mathrm{~kg} \cdot \mathrm{m}^{2}\right)$ with & 81.7 \\
CVS or respiratory complications & \\
Morbid obesity $\left(\mathrm{BMI}>=45 \mathrm{~kg} \cdot \mathrm{m}^{2}\right.$ ) with & 95.2 \\
CVS or respiratory complications & \\
No escort & 88.1 \\
\hline
\end{tabular}

ASA $=$ American Society of Anesthesiologists physical status; AP = angina pectoris - Canadian Cardiovascular Society Functional Classification $; \mathrm{MI}=$ myocardial infarction $; \mathrm{CHF}=$ congestive heart failure - New York Heart Association Classification; GA = general anesthesia; $\mathrm{BMI}=$ body mass index; $\mathrm{CVS}=$ cardiovascular.

Our survey demonstrated that medical conditions with extreme grades of severity are associated with majority opinion to proceed or not to proceed with ambulatory surgery, while intermediate grades of severity are associated with disparity of opinion. The changing practices of ambulatory anesthesia are reflected throughout the questionnaire. In the early days of ambulatory surgery, only ASA status I to II patients were considered suitable for ambulatory 
surgery. Now however, providing anesthesia to ASA III patients is a common practice among our responders $(93.9 \%)$. ASA class IV patients were still considered by $82.4 \%$ of responders to be unfit for ambulatory surgery. It is interesting to note, however, that chronic renal failure patients, who by definition are ASA class IV were acceptable to $72 \%$ of responders later in the questionnaire. Conditions such as ASA I to II and AP class I, were not presented in the questionnaire since these patients are routinely anesthetized for ambulatory surgery.

When presented with cardiac issues, the majority of the responding anesthesiologists were willing to provide ambulatory anesthesia to patients with low-grade or remote symptoms i.e., AP class II (96.4\%), CHF class I (93.5\%), MI occurring more then six months before surgery and asymptomatic valvular disease. These conditions are clearly acceptable for ambulatory surgery.

Surprisingly, only $15.9 \%$ of responders would anesthetize a patient one to six months after his MI. The American Heart Association/American College of Cardiology Guidelines place this patient in the intermediate clinical predictor group for perioperative cardiovascular risk. ${ }^{5}$ Isolated intermediate predictors are considered safe for surgery, especially in the settings of ambulatory procedures which are defined as low-risk surgery. Only a recent MI, defined as less than 30 days, places the patient in the major clinical predictor group, which mandates cancellation of non-urgent surgery. So while evidence-based medicine indicates that patients presenting for surgery more than 30 days after their MI are probably safe candidates for ambulatory surgery, the majority of our responders do not practice accordingly. On the other hand, two thirds of the responders $(66.3 \%)$ would agree to anesthetize an AP class III patient, which is a major clinical predictor according to the same guidelines, indicating surgery should be cancelled. These views demonstrate some of the contradictions between clinical practices, expert views and published guidelines.

MO with a BMI of 35 to $44 \mathrm{~kg} \cdot \mathrm{m}^{-2}$, without added pathology, was considered an acceptable risk by $91 \%$ of the responders. As recently as 1992 a patient with a BMI $>30 \mathrm{~kg} \cdot \mathrm{m}^{-2}$ was considered unsuitable for ambulatory surgery by the Royal College of Surgeons of England. ${ }^{6}$ Although obese patients have an increased risk of perioperative complications, ${ }^{7}$ the majority of units surveyed by Atkins routinely disregarded these guidelines and anesthetized patients with a $\mathrm{BMI}>30$ $\mathrm{kg} \cdot \mathrm{m}^{-2}{ }^{8}$ A study of 258 morbidly obese patients undergoing ambulatory surgery did not reveal any significant increase in unplanned admissions or complications. ${ }^{9}$
With the prevalence of obesity increasing worldwide, clear and current guidelines need to be formulated. ${ }^{10}$

Obstructive sleep apnea in the ambulatory surgery setting has become a more significant concern in recent years, being a critical part of preoperative patients' risk assessment. In a random sample of employed Americans aged 30 to $60 \mathrm{yr}, 9 \%$ of women and $24 \%$ of men had index scores compatible with the diagnosis of sleep apnea. ${ }^{11}$

The majority of responders in our survey $(97 \%)$ would anesthetize sleep apnea patients if GA and narcotic substances are not used (e.g., regional anesthesia) but would otherwise exclude these patients. There is very little literature on sleep apnea in ambulatory surgery and no clear guidelines. The patient's estimated need for apnea monitoring and continuous positive airway pressure and the likelihood of his safe discharge without developing airway obstruction will help determine his eligibility for ambulatory surgery.

IDDM was not considered a contraindication for ambulatory surgery $(92.8 \%)$. A study looking at preexisting medical conditions as predictors of adverse events in day-case surgery did not find IDDM to be a significant predictor of intra- or postoperative events in ambulatory surgery. ${ }^{3}$

$\mathrm{MH}$ was presented as either proven or in a patient susceptible to it. Although the approach to both these types of patient would be identical, the answers differed. Most responders (82\%) would anesthetize susceptible patients as opposed to only $49.7 \%$ for proven MH. In a study on 2,214 MHS patients, only five showed immediate postoperative mild symptoms of hyperthermia, in none of which could a clinical episode of $\mathrm{MH}$ be confirmed. ${ }^{12}$ In a ten-year review of MHS children there were no incidences of clinical $\mathrm{MH}$. The authors conclude that postoperative admission to the hospital solely on the basis of the MH susceptibility label is not warranted. ${ }^{13}$ The $\mathrm{MH}$ Association of the United States maintains that MHS patients can safely undergo ambulatory surgery. ${ }^{14}$ The Society for Ambulatory Anesthesia states that MHS is not a contraindication to outpatient surgery. ${ }^{15} \mathrm{MH}$ patients undergoing a non-triggering anesthesia may therefore be safely anesthetized as ambulatory patients.

An increasing number of elderly patients are undergoing ambulatory surgery. Close to $60 \%$ of responders would provide anesthesia to patients over $90 \mathrm{yr}$ old. Previous studies have shown that elderly patients have a higher incidence of any intraoperative event (adjusted odds ratio, 1.4) and a twofold higher risk for intraoperative cardiac event. ${ }^{4}$ These risks do not constitute a contraindication for ambulatory surgery but this population may require more careful management. 
Sickle cell patients are accepted by some centres for short procedures with minimal blood loss and no tourniquet use. Since even the recommendations on hemoglobin levels before surgery are not decisive, no single measure can replace good clinical judgment on appropriateness for ambulatory surgery. ${ }^{16}$ Recent guidelines advocated increasing the hematocrit to about $30 \%$ by preoperative transfusion for patients undergoing GA. ${ }^{17}$ The authors also suggested considering overnight observation. The rationale behind this is that since acute chest syndrome has its peak effect $48 \mathrm{hr}$ after surgery, a prolonged postoperative observation is desirable.

The subject of discharging a patient only with a responsible adult escort is one of the few issues discussed here for which the guidelines are clear, although this may be an issue imposed by hospital policies and legal rather than clinical considerations. ${ }^{18,19}$ Still, more then $10 \%$ of the responders would agree to anesthetize an unescorted patient. Some of these anesthesiologists added that they would only agree if the patient signed a release form. There is no literature to support this measure as being medicolegaly adequate.

Surprisingly, approximately $70 \%$ of the responding anesthesiologists would agree to anesthetize patients with signs of acute substance abuse. Many centres include acute substance abuse in their exclusion criteria because of the increased risk for untoward cardiovascular responses, and withdrawal problems. The ASA guidelines for office-based anesthesia include even a history of alcohol or substance abuse as a factor to be considered when deciding whether anesthesia in the office setting is appropriate. ${ }^{20}$ We feel that non-urgent procedures should be postponed when substance abuse is recognized.

The management of patients receiving monoamine oxidase inhibitors (MAOIs) continues to be challenging due to the potential for deleterious drug interactions. However, recent clinical experience has demonstrated the relative safety of continuing MAOIs treatment through surgery by use of specific 'MAOI safe' anesthetic techniques and/or substitution of short-acting MAOIs which do not irreversibly inhibit the enzyme. ${ }^{21}$ Most of our responders (69.5\%) find that MAOI use should not prevent ambulatory surgery.

There are several limitations to our survey. Firstly, demographic data were not collected and we are therefore unable to stratify our results according to certain demographic subgroups (e.g., age, level of experience, affiliation with an academic centre). Secondly, surgical procedures were not specified. The omission was intentional in order to keep the survey simple and general. Extensive procedures, which are done routinely as ambulatory cases in some centres are performed as inpatient surgery only in others. ${ }^{2}$ Since we were looking at patient selection we did not find naming each of the numerous ambulatory procedures necessary. We still felt comfortable with grouping the example procedures given in the questionnaire since they are all considered low-risk procedures. ${ }^{5}$ The response rate of $60 \%$, although relatively high for this wide distribution questionnaire may still have a biased response pattern influencing the results.

The survey tool was constructed to answer the salient points of patient selection and is otherwise unvalidated. Because of the limits imposed for data analysis, as well as for clarity of the questionnaire, only yes/no answers were permitted, thus limiting flexibility and possibly forcing answers, which may have been different otherwise. Although a grading scale for gradations of agreement may have also been appropriate it would have complicated the data analysis and possibly even decreased the response rate that is essential for this type of questionnaire. The ASA obtains consensus data from multiple sources, including surveys of expert consultants and of the broader population of practitioners. The surveys are in a agree/disagree format and designed so that responses are easily interpreted and differences clearly noted. ${ }^{19,22}$

The data acquired in our questionnaire and in future studies may help in formulating selection criteria for ambulatory surgery. It is obvious from the answers that some of the conditions, especially those corresponding to the two extremes of the clinical range are in agreement. It is difficult to provide a "magical figure" representing an accepted consensus, although the figure of $75 \%$ agreement is often used and was a part of our results observation analysis. The ASA uses an even lower number of $65 \%$ for the average weighted response in the survey part of the guideline formulation as indicating agreement on issues. ${ }^{19}$ The $75 \%$ agreement mark on controversial issues presented in our questionnaire reflects the current practice in ambulatory anesthesia by the majority of anesthesiologists. Although a limited tool, this survey combined with prospective outcome studies may serve as a future guide for changing the individual and institutional practice of those who practice ambulatory anesthesia more conservatively.

In conclusion, our survey shows the current clinical practice of ambulatory adult patient selection regarding some controversial issues. Further population studies, especially in the areas of controversy, are needed in order to establish safety guidelines for ambulatory surgery patient selection. 


\section{Acknowledgement}

The authors wish to thank the members of the Canadian Anesthesiologists' Society for their participation in this survey.

\section{APPENDIX Questionnaire}

Ambulatory anesthesia adult patient selection criteria

Would you provide ambulatory anesthesia for an adult patient with the following isolated condition? The Surgical procedure may be done under general anesthesia (for example - knee arthroscopy, gynecologic hysteroscopy or laparoscopic cholecystectomy).

American Society of Anesthesiologists' (ASA)

ASA status III stable patients

Yes No

ASA status IV stable patients

Yes No

Angina pectoris (AP)

AP class II - walking greater than two

blocks, climbing greater then one flight Yes No

of stairs

AP class III - walking one to two blocks, Yes No

climbing one flight of stairs

AP class IV - symptoms with daily Yes No

activities, or present at rest

Prior MI (one to six months

Yes No

before surgery)

Prior MI (more than six months $\quad$ Yes No

before surgery)

Congestive heart failure (CHF)

CHF, NYHA class I: symptoms with Yes No

strenuous activity

CHF, NYHA class II: symptoms $\quad$ Yes No

with moderate activity

CHF, NYHA class III: symptoms $\quad$ Yes No

with mild activity

CHF, NYHA class IV: symptoms at rest Yes No

Asymptomatic valvular heart disease Yes No

\section{Sleep apnea}

Under monitored anesthesia care $\quad$ Yes No

Under regional anesthesia, does not Yes No

require narcotic analgesia postoperatively

Under regional anesthesia, requires Yes No

narcotic analgesia postoperatively

Under general anesthesia, does not Yes No

require narcotic analgesia postoperatively

Under general anesthesia, requires

narcotic analgesia postoperatively

\section{Morbid obesity}

$\left(\mathrm{BMI}=35-44 \mathrm{~kg} \cdot \mathrm{m}^{2}\right)$ without

Yes No

cardiovascular or respiratory

complications

$\left(\mathrm{BMI}=35-44 \mathrm{~kg} \cdot \mathrm{m}^{2}\right)$ with

Yes No

cardiovascular or respiratory

complications

$\left(\mathrm{BMI}>45 \mathrm{~kg} \cdot \mathrm{m}^{2}\right)$ without

cardiovascular or respiratory

complications

$\left(\mathrm{BMI}>45 \mathrm{~kg} \cdot \mathrm{m}^{2}\right)$ with

cardiovascular or respiratory

complications

Insulin dependent diabetes mellitus Yes No

Malignant hyperthermia susceptibility Yes No

Proven malignant hyperthermia $\quad$ Yes No

Active substance abuse $\quad$ Yes No

Patient on concurrent MAOI treatment Yes No

Sickle cell anemia $\quad$ Yes No

Chronic renal failure (hemo or $\quad$ Yes No

peritoneal dialysis)

Age $>90$

No escort

Yes No

Yes No

If you have any additional selection criteria not addressed here, or any other comments concerning the subject please add your comments here.

\section{References}

1 Twersky RS, Showan AM. Office-based anesthesia update: guidelines, education and support are invaluable. ASA Newsletter 1999; 63: 22-4.

2 White PF. Ambulatory anesthesia advances into the new millennium. Anesth Analg 2000; 90: 1234-5.

3 Chung F, Mezei G, Tong D. Pre-existing medical conditions as predictors of adverse events in day-case surgery. Br J Anaesth 1999; 83: 262-70.

4 Chung F, Mezei G, Tong D. Adverse events in ambulatory surgery. A comparison between elderly and younger patients. Can J Anesth 1999; 46: 309-21.

5 Eagle KA, Berger PB, Calkins H, et al. ACC/AHA guideline update for perioperative cardiovascular evaluation for noncardiac surgery-executive summary. A report of the American College of Cardiology/American Heart Association Task Force on Practice Guidelines (committee to update the 1996 guidelines on perioperative cardiovascular evaluation for noncardiac surgery). Anesth Analg 2002; 94: 1052-64.

6 Commission on the Provision of Surgical Services. Guidelines for Day Case Surgery. A Report of the Royal College of Surgeons of England, revised edition. London: Royal College of Surgeons of England; 1992. 
7 Adams JP, Murphy PG. Obesity in anaesthesia and intensive care. Br J Anaesth 2000; 85: 91-108.

8 Atkins $M$, White J, Ahmed K. Day surgery and body mass index: results of a national survey. Anaesthesia 2002; 57: 169-82.

9 Davies KE, Houghton K, Montgomery JE. Obesity and day-case surgery. Anaesthesia 2001; 56: 1112-5.

10 Bjorntorp P. Obesity. Lancet 1997; 350: 423-6.

11 Young T, Palta M, Dempsey J, Skatrud J, Weber S, Badr $S$. The occurrence of sleep-disordered breathing among middle-aged adults. N Engl J Med 1993; 328: 1230-5.

12 Carr AS, Lerman J, Cunliffe M, McLeod ME, Britt BA. Incidence of malignant hyperthermia reactions in 2,214 patients undergoing muscle biopsy. Can J Anaesth 1995; 42: 281-6.

13 rentis SM, Levine MF, Hartley EJ. Should all children with suspected or confirmed malignant hyperthermia susceptibility be admitted after surgery? A 10-year review. Anesth Analg 1992; 75: 345-50.

14 Malignat Hyperthermia Association of the United States. Medical FAQs. Available from URL; http://www.mhaus.org/index.cfm/fuseaction/Conten t.Display/PagePK/MedicalFAQs.cfm.

15 American Society of Anesthesiologists Committee on Ambulatory Surgical Care and the American Society of Anesthesiologists Task Force on Office-Based Anesthesia. Considerations for anesthesiologists in setting up and maintaining a safe office anesthesia environment. Available from URL; http://www.asahq.org/ publicationsAndServices/office.htm\#malignant.

16 National Institutes of Health. National Heart, Lung, and Blood Institute. Division of Blood Diseases and Resources. The Management of Sickle Cell Disease, 4th ed. Rev June 2002. Bethesda, Md.: National Heart, Lung, and Blood Institute; July 2002.

17 Steinberg $M H$. Management of sickle cell disease. N Engl J Med 1999; 340: 1021-30.

18 American Society of Anesthesiologists. Guidelines for ambulatory anesthesia and surgery. Available from URL; http://www.asahq.org/publications AndServices/standards/04.html.

19 Silverstein JH, Apfelbaum JL, Barlow JC, et al. Practice Guidelines for Postanesthetic Care. A report by the American Society of Anesthesiologists Task Force on Postanesthetic Care. Anesthesiology 2002; 96: 742-52.

20 American Society of Anesthesiologists Committee on Ambulatory Surgical Care and the American Society of Anesthesiologists Task Force on Office-Based Anesthesia. Considerations for anesthesiologists in setting up and maintaining a safe office anesthesia environment. An informational manual. Available from URL; http:// www.asahq.org/publicationsAndServices/office.htm\#prep.
21 Smith MS, Muir H, Hall R. Perioperative management of drug therapy. Clinical considerations. Drugs 1996; 51: 238-59.

22 Connis RT, Nickinovich DG, Caplan RA, Arens JF. The development of evidence-based clinical practice guidelines. Integrating medical science and practice. Int J Technol Assess Health Care 2000; 16: 1003-12. 